\title{
A DIGNIDADE HUMANA NO PENSAMENTO DE KANT COMO FUNDAMENTO DO PRINCÍPIO DA LEALDADE PROCESSUAL
}

\section{THE HUMAN DIGNITY IN THOUGHT OF IMMANUEL KANT AS FOUNDATION OF THE PRINCIPLE OF PROCEDURAL FAIRNESS}

\author{
Vinicius Pinheiro Marques ${ }^{1}$ \\ Sérgio Augusto Pereira Lorentino ${ }^{2}$ \\ Rubem Ribeiro de Carvalho ${ }^{3}$
}

\begin{abstract}
RESUMO:
Este artigo teve como delimitação de tema e também questão central a possibilidade da aplicação do pensamento Kantiano sobre dignidade humana como fundamento do princípio lealdade processual. Para tanto, não só identificou a idéia do autor como, brevemente, descreveu a natureza jurídica da jurisdição, da relação jurídica processual, para relacionar ao final com o princípio da lealdade processual. A relevância do artigo está na evidente necessidade de se ter movimentos teóricos e construções normativas que acompanhem as transformações sociais considerando um sistema que vem se fundamentando na dignidade humana, sendo objetivo essencial na construção de uma sociedade livre, justa e solidária. Utilizando-se como referencial teórico a idéia de dignidade aventada pelo filósofo Immanuel Kant, foi desenvolvida uma pesquisa exploratória com abordagem qualitativa, cuja vertente metodológica é de procedimento bibliográfico teórico-documental, sob um ângulo dogmático, utilizada como forma de analisar os resultados. Concluiu-se que a percepção Kantiana sobre a dignidade humana pode fundamentar o princípio da lealdade processual.
\end{abstract}

PALAVRAS-CHAVE: Dignidade humana; Pensamento kantiano; Princípio da lealdade processual.

\section{ABSTRACT:}

This article had the delimitation of the subject and also central question the possibility of the application of Kantian thinking about human dignity as the foundation of the principle of procedural fairness. Therefore, not only identified the idea of the author as briefly described the legal nature of jurisdiction, procedural legal relationship, relate to the end with the principle of procedural fairness. Its relevance is in obvious need of having movements and theoretical constructs normative accompanying social transformations considering a system that has been basing on human dignity, being essential objective in building a free society, fair and supportive. Not admitting, thereby, that economic activity can override these values and fundamental objectives. Using as a theoretical idea of dignity mooted by the philosopher

\footnotetext{
${ }^{1}$ Doutorando em Direito pela Pontifícia Universidade Católica de Minas Gerais (PUC MINAS). Professor de Direito da Universidade Federal do Tocantins (UFT). E-mail: viniciusmarques@uft.edu.br

${ }^{2}$ Doutorando em Direito pela Pontifícia Universidade Católica de Minas Gerais (PUC MINAS). Professor de Direito da Universidade Federal do Tocantins (UFT). E-mail: sergiolorentino@ uft.edu.br

${ }^{3}$ Mestrando em Prestação Jurisdicional e Direitos Humanos pela Universidade Federal do Tocantins (UFT). Juiz de Direito da Comarca de Palmas/TO. E-mail: rubem@tjto.jus.br
} 
Immanuel Kant, was developed an exploratory study with a qualitative approach, which methodological line is procedural literature theoretical and documentary under a dogmatic approach, used in order to analyze the results. It was concluded that the Kantian insight about human dignity can support the principle of procedural fairness.

KEY-WORDS: Human dignity; Kantian thought; Principle of procedural fairness.

\section{INTRODUÇÃO}

Sendo o processo por sua natureza eminentemente dialético, é reprovável que as partes se sirvam dele faltando ao dever de verdade, agindo deslealmente e empregando meios fraudulentos. $O$ processo é um instrumento posto à disposição das partes não somente para a eliminação de conflitos e para que possam obter respostas às suas pretensões, mas é, antes de tudo, para a pacificação geral na sociedade e para a atuação do direito.

Diante dessas finalidades, que the outorgam uma profunda inserção sociopolítica, deve o processo se revestir de uma dignidade que corresponda a seus fins. Segundo Cintra et alli (2001), o princípio que impõe esses deveres de moralidade e probidade a todos aqueles que participam do processo (juiz, partes, auxiliares da justiça, advogados e membros do Ministério Público), denomina-se princípio da lealdade processual. Por este princípio, o processo não pode prestar-se ao abuso de direito. As regras processuais condensadas naquele princípio visam exatamente conter os litigantes e a lhes impor uma conduta que possa levar o processo à consecução de seus objetivos.

Embora o princípio da lealdade processual seja reconhecido pela doutrina e positivado no art. 14, inciso II, do Código de Processo Civil, tem-se como problema do presente artigo saber se é possível encontrar um substrato axiológico e filosófico para o referido princípio processual. Nesse sentido, o objetivo geral deste artigo é demonstrar que o princípio da lealdade processual pode ser sustentado na ideia de dignidade humana de Immanuel Kant.

Para alcançar o objetivo geral deste trabalho, será abordado inicialmente o conceito de jurisdição e direito processual, assim como as suas características, para, posteriormente, compreender o que vem a ser a relação jurídica processual e, sobretudo, quem a integra. Com estes conceitos fixados, é que se abordará 
detalhadamente a previsão normativa da lealdade processual para, ao final, correlacionar com a ideia de dignidade humana de Immanuel Kant.

\section{JURISDIÇÃO E DIREITO PROCESSUAL}

Na lição de Theodoro Junior (2008) é impossível a vida em sociedade sem uma normatização do comportamento humano. Daí surgir o Direito como conjunto de normas gerais e positivas, disciplinadoras da vida social. Mas não basta traçar a norma de conduta. O equilíbrio e o desenvolvimento sociais só ocorrem se a observância das regras jurídicas fizer-se obrigatória. Assim, o Estado não apenas cuida de elaborar leis, ma também institui meios de imposição coativa do comando expresso da norma.

Lado outro, diante das complexas relações sociais travadas, é impossível evitar conflitos de interesse entre cidadãos, ou entre esses e o próprio Estado, a respeito da interpretação de direitos subjetivos e da correta aplicação do direito objetivo aos casos concretos.

Para manter o império da ordem jurídica e assegurar a paz social, o Estado se utiliza da função de jurisdição, que incumbe ao Poder Judiciário, para exercer a missão pacificadora diante das situações litigiosas. Através dessa função, Carnelutti (1956) afirma que o Estado dá solução aos litígios, que são conflitos de interesse caracterizados por pretensões resistidas, tendo como objetivo imediato a aplicação da lei ao caso concreto apresentado e, como missão mediata, restabelecer a paz entre os particulares e, com isso, manter a da sociedade.

Para cumprir essa tarefa, o estado utiliza método próprio que se denomina processo. Não obstante, com o intuito de regular esse método de composição do litígio, é que o Estado cria normas jurídicas que formam o direito processual. Diante desse quadro, Chiovenda (1969, p. 37) conceitua este como "ramo da ciência jurídica que trata do complexo das normas reguladoras do exercício da jurisdição".

Conforme leciona Theodoro Junior (2008), a autonomia do direito processual frente ao direito substancial é inegável e se caracteriza por total diversidade de natureza e de objetivos. Enquanto o direito material cuida de estabelecer as normas que regulam as relações jurídicas entre pessoas, o processual visa a regulamentar uma função pública estatal, sendo que seus princípios estão todos ligados ao direito 
público. Desta forma deve-se registrar que, mesmo quando o conflito de interesses for eminentemente privado, há no processo sempre um interesse público.

\section{RELAÇÃO JURÍDICA PROCESSUAL E SUJEITOS DO PROCESSO}

Nas considerações de Lacerda (2007) a relação jurídica de direito processual é formada por demandante, demandado e pelo Estado-juiz, sendo esta composição mínima. Diante da presença desses três sujeitos, que se verifica normalmente nos casos concretos, sendo dois parciais (demandante e demandado) e um imparcial (juiz), é tranquilo o entendimento de que a relação jurídica processual é tríplice.

Conforme registra Neves (2011), existe um dissenso doutrinário a respeito de a relação jurídica processual tríplice ser triangular ou angular. No primeiro caso todos os sujeitos têm relação direta (posições jurídicas) entre si, inclusive demandante e demando; enquanto que no segundo caso a relação entre esses dois sujeitos é indireta, passando sempre pelo juiz.

Cumpre consignar a superioridade do entendimento de que a relação jurídica processual é triangular, sendo inegável a existência de posições jurídicas diretas entre demandante e demandado, sobretudo pelo dever de lealdade processual a ser recíproca entre as partes, conforme destaca o art. 14, inciso II, do Código de Processo Civil.

Bueno (2007), ao abordar sobre as características da relação jurídica processual, destaca a autonomia desta em relação à de direito material, na medida em que, mesmo não existindo a segunda, existirá a primeira. Também é complexa em decorrência das inúmeras e sucessivas situações jurídicas que se verificam durante o trâmite procedimental, pois as partes têm ônus, faculdades, direitos e deveres e estão em estado de sujeição. A relação jurídica processual é continuada, desenvolvendo-se durante um tempo, e interligadas de forma lógica, conferindo aos atos processuais uma unidade.

O primeiro sujeito da relação processual a ser analisado é o Estado-juiz, este ocupa uma posição de supremacia e equidistância das partes. Conforme elucida Câmara (2008), a supremacia decorre do fato de o processo ser um instrumento de exercício do poder sobreano do Estado, através de uma de suas manifestações, qual seja, a jurisdição. Já a equidistância, que nada mais é do que a demonstração 
gráfica da imparcialidade, é o corolário da substitutividade da vontade das partes pela decisão do Poder Judiciário.Importante observar que os auxiliares da justiça são todos aqueles que contribuem com o juiz para a realização das funções do juízo e, justamente por desempenharem funções relevantes no processo, merecem tratamento e regulamentação específicos.

É tradicional o conceito de partes como sendo aquele que pleiteia e aquele em face de quem se pleiteia a tutela jurisdicional. Entretanto, seguindo o entendimento de Câmara (2008), aquele conceito se refere à partes da demanda (autor e réu), enquanto que é possível dizer que existem partes do processo, ou seja, todas aquelas pessoas que participam do procedimento em contraditório alterando o esquema mínimo que se fez referência à estrutura tríplice. Nessa toada, conforme observa Dinamarco (1998), é que a qualidade de parte pode ser adquirida de quatro formas: pela demanda, pela citação, pela sucessão e pela intervenção.

As partes possuem deveres que devem ser cumpridos ao longo do processo, sendo que um deles, conforme se verá no capítulo seguinte, é o da lealdade processual.

\section{O PRINCÍPIO DA LEALDADE PROCESSUAL}

O princípio da lealdade processual encontra manifestação expressa no art. 14 do Código de Processo Civil, quando este ao descrever aos deveres das partes assim enunciou:

Art. 14. São deveres das partes e de todos aqueles que de qualquer forma participam do processo:

I - expor os fatos em juízo conforme a verdade;

II - proceder com lealdade e boa-fé;

III - não formular pretensões, nem alegar defesa, cientes de que estão destituídas de fundamento;

IV - não produzir provas, nem praticar atos inúteis ou desnecessários à declaração ou defesa do direito;

$\mathrm{V}$ - cumprir com exatidão os provimentos mandamentais e não criar embaraços à efetivação de provimentos judiciais, de natureza antecipatória ou final. 
Tais deveres, em verdade, poderiam ser reduzidos em uma única frase: cabe às partes o dever de auxiliar o juízo no descobrimento da verdade e na efetivação das decisões judiciais, sem utilizar expedientes antiéticos.

Sobre o princípio da lealdade processual, Wambier et alli (2008) enfatiza que o comportamento das partes e de todos os envolvidos no processo deve respeitar os preceitos relativos à boa-fé, repugnando o sistema o comportamento desleal. Não obstante, Donizetti (2013), enfatiza que este princípio impõe a todos que participam do processo deveres de moralidade e probidade.

Não obstante, a lealdade processual deve ser reconhecida como princípio pelas razões a seguir expostas.

A doutrina, especialmente após a obra de Alexy (2008), tem feito a distinção entre princípios e regras. Enquanto as regras se esgotam em si mesmas, na medida em que descrevem o que se deve, não se deve ou se pode fazer em determinados momentos, os princípios são constitutivos da ordem jurídica, revelando os valores ou os critérios que devem orientar a compreensão e a aplicação das regras diante das situações concretas.

Alexy (2008) afirma que os princípios são normas que ordenam que algo seja realizado na maior medida possível, dentro das possibilidades jurídicas e fáticas existentes, ao passo que as regras são normas que podem ser cumpridas ou não, uma vez que, se uma regra é válida há de ser feito expressamente o que ela exige, nem mais nem menos. De acordo com o citado autor, as regras contêm determinações em um âmbito fático e juridicamente possível, ao passo que os princípios podem ser realizados em diferentes graus, consoante às possibilidades fáticas e jurídicas.

Conforme assevera Marinoni (2007), os princípios não tem limitação, pois eles são razões para juízos concretos do dever ser. Os princípios recortam certas parcelas da realidade e colocam-nas sob seu âmbito de proteção. Consequentemente, a partir do momento em que se projetam sobre a realidade, eles servem de fundamento para normas específicas que orientam concretamente a ação, seja num sentido positivo (prestação fática ou jurídica), seja num sentido negativo (omissão).

Portanto, agir com lealdade no processo é um valor que deve ser buscado, que não esgota em si mesmo, devendo ser um princípio balizador para a confecção de novas leis processuais e até para aplicação do direito no caso concreto. 
É claro que a compreensão do Direito por meio dos princípios, conforme proposta de Britto (2003), implica em uma ruptura com o positivismo do Estado liberal, que se expressa em um Direito constituído por regras.

O positivismo clássico, temendo que os princípios pudessem provocar uma profunda imprevisibilidade em relação às decisões judiciais, acarretando incerteza quanto ao significado do Direito, concluiu que a atividade com os princípios deveria ser reservada a um órgão político, já que não se amoldava com a função que era esperada do juiz, isto é, uma simples aplicação do ditado da regra produzida e acabada pelo legislativo.

No atual Estado contemporâneo, caracterizado pela força normativa da constituição (HESSE, 1991), obviamente não se dispensa a conformação das regras aos princípios e sabe que isso apenas pode ser feito com o auxílio da jurisdição.

\subsection{Lealdade objetiva}

Lealdade processual não é um elemento dependente da disposição voluntária das partes. Antes disso, lealde é uma condição objetiva da qual depende o processo civil para sua efetiva operacionalização, mormente a partir da ideia de paridade de armas e do bom combate.

O tratamento normativo da lealdade Ihe confere caráter objetivo, na mesma acepção do que ocorre com o princípio da boa-fé objetiva, no regramento do universo do direito contratual.

Assim, é possível afirmar que a não observância dos deveres de lealdade conferem aos atos do processo um caráter de relatividade, máxime diante da evidência de prejuízo a qualquer dos sujeitos lesados pelo ato, bem como à própria jurisdição.

A postura das partes diante do processo deve ser, antes de qualquer coisa, cooperativa, porque o processo, embora não seja um fim em si mesmo, é, de outro lado, um bem valioso para a ordem jurídica e para as partes, enquanto cidadela da efetivação de seus direitos.

Ferraz Junior, afirma que a solidariedade social (nesse caso a disposição das partes em colaborar com lealdade para com o processo) exige, para sua consecução, de "uma força exterior, respeitável e temida" (2003, p.355). 
De fato, a norma estampada no artigo 14, do Código de Processo Civil, aparece como elemento norteador da conduta, mas principalmente, como fator de regência dos eventuais desvios.

Entretanto, embora o trato da lealdade, através de uma devoção à previsão normativa, remeta a um estado dogmático do tema, na verdade, a visão do julgador deve ser pós-positivista, na medida em que o valor da lealdade acompanha, em tamanho e qualidade, a arquitetura social de cada momento (tempus regit actum).

Portanto, a lealdade processual enseja uma visão abrangente do julgador, até mesmo para que o caráter de objetividade deste valor processual, não se torne uma norma meramente formal, abstrata e anacrônica.

\section{A DIGNIDADE HUMANA NA CONSTITUIÇÃO FEDERAL DE 1988}

Com muito atraso, o Brasil encartou em sua Constituição Republicana de 1988 o espírito dos valores mencionados na Declaração Universal dos Direitos Humanos, de 1948.

Expressamente, na Constituição, a dignidade humana foi alçada a um princípio estrutural da República que emana sobre todo o ordenamento jurídico sua influência axiológica.

De fato a Constituição brasileira, a partir da construção do ideal normativo da dignidade da pessoa humana, prescrito logo no seu primeiro artigo, ditou a tônica da nova ordem jurídica que se propagou pela tutela do homem em suas múltiplas dimensões, máxime no tocante à relação do homem com a força e os instrumentos do Estado.

Os chamados remédios constitucionais (habeas corpus, habeas data, mandado de injunção, mandado de segurança), são um claro exemplo de armas pré-programadas à defesa da pessoa e de seus direitos fundamentais.

Em todo campo da ação política, social e jurídica o valor da dignidade da pessoa humana foi projetado e não se pode mais considerar uma hermenêutica puritana que somente leve em conta o sentido restrito do sistema jurídico a que pertence.

Ao contrário disso, todo e qualquer sistema jurídico, por mais autônomo acadêmica e dogmaticamente que pareça ser, deve manter profundo diálogo e 
harmonia com a Constituição Federal e com o valor da dignidade da pessoa humana.

Hesse (1991, p. 3), sobre a influência dos valores decorrentes da ordem constitucional, pontuou que

Há de ser, igualmente, contemplado o substrato espiritual que se consubstancia num determinado povo, isto é, as concepções sociais concretas e o baldrame axiológico que influenciam decisivamente a conformação, o entendimento e a autoridade das proposições normativas.

Logo, é possível concluir que, no cenário do Direito Processual Civil, o valor da pessoa humana deve ser observado não apenas como pressuposto de validade dos atos processuais propriamente ditos, mas como meta a ser atingida. Na visão de Robert Alexy, esta ideia pode ser visualizada sob a rubrica da otimização, ou seja, quanto mais o processo civil servir ao ideal do ser humano digno, mais cumprirá com seu desiderato constitucional e valorativo (2008, p.90).

Assim, se a lealdade processual contribui - e de fato contribui - para uma relação processual em que a dignidade humana é levada a efeito, temos que aquele valor é constitucionalmente aceito porque otimiza este. Nada mais correto, portanto, afirmar que a lealdade processual tem lastro constitucional na dignidade da pessoa humana, dentre outras coisas, porque promove uma disputa processual igualitária, ética e, por decorrência, justa.

Aliás, convém registrar que a dignidade da pessoa humana, à luz da Constituição Federal de 1988, e, de acordo com a visão de Alexandre de Moraes, "é um valor espiritual e moral inerente à pessoa, que se manifesta singularmente na autodeterminação consciente e responsável da própria vida e que traz consigo a pretensão ao respeito..."(2013, p.18)

A dignidade da pessoa humana, é, portanto, na Constituição Federal de 1988, um valor agregador dos direitos fundamentais do homem, com caráter unificador, conforme menciona José Afonso da Silva, "concebido como referência constitucional unificadora..." (2008, p.105.). 


\section{A IDEIA DE DIGNIDADE HUMANA NO ORDENAMENTO JURÍDICO E NO PENSAMENTO DE IMMANUEL KANT}

É difícil negar a importância teórica e prática do conceito de dignidade humana. Além disso, trata-se de uma noção que pode ser abordada a partir de uma grande variedade de perspectivas e disciplinas, pois é uma ideia que tem aplicações em diversas esferas da vida humana. Apesar de existir um consenso quase absoluto em torno da dignidade humana como ideia fundadora dos direitos humanos, Bobbio (1991) destaca que o significado e alcance concreto dessa ideia apresenta, ao contrário, um desacordo generalizado e amplo. Não obstante, Sarlet (2006, p. 46) afirma que a dignidade da pessoa humana consiste na

qualidade intrínseca e distintiva de cada ser humano que o faz
merecedor do mesmo respeito e consideração por parte do Estado e
da comunidade, implicando, neste sentido, um complexo de direitos e
deveres fundamentais que assegurem a pessoa tanto contra todo e
qualquer ato de cunho degradante e desumano, como venham a lhe
garantir as condições existentes mínimas para uma vida saudável,
além de propiciar e promover sua participação ativa e co-responsável
nos destinos da própria existência e da vida em comunhão com os
demais seres humanos.

Mas se reconhece a importância da dignidade humana, embora existam os dissensos, qual a finalidade de se mantê-la positivas nas constituições? Habermas (2003) sustenta que a constituição da forma jurídica torna-se necessária a fim de compensar déficits da moral, uma vez que algumas normas de ação, para alcançar ampla eficácia, carecem não só de juízos corretos e equitativos da moral, mas também, de forma complementar, da obrigatoriedade legitimamente imposta, com o poder de coação, próprio do Direito. Daí se intui que a positivação do princípio da dignidade da pessoa humana, em virtude do valor que esse ostenta, resulta da urgência de sua plena efetividade, que não pode ser satisfatoriamente garantida apenas através de um mandamento moral.

No Brasil, ainda antes de entrar em vigor a atual Constituição, Comparato (1989, p. 46) afirma que o "núcleo essencial dos direitos humanos reside na vida e na dignidade da pessoa". Nessa perspectiva, Guerra Filho (2005, p. 62-63) destaca a posição da dignidade da pessoa humana frente aos princípios constitucionais:

Os direitos fundamentais, portanto, estariam consagrados objetivamente em "princípios constitucionais especiais", que seriam a 


\begin{abstract}
"densificação" (Canotilho) ou "concretização" (embora em nível extremamente abstrato) daquele "princípio fundamental geral", de respeito à dignidade humana. Dele, também, se deduziria o já mencionado "princípio da proporcionalidade", até como uma necessidade lógica, além de política, pois se os diversos direitos fundamentais estão, abstratamente, perfeitamente compatibilizados, concretamente se dariam as "colisões" entre eles, quando então, recorrendo a esse princípio, se privilegiaria, circunstancialmente, alguns direitos fundamentais em conflito, mas sem com isso chegar a atingir outro dos direitos fundamentais conflitantes em seu conteúdo essencial.
\end{abstract}

Para se compreender a ideia de dignidade em Kant é necessário, preliminarmente, compreender o que venha a ser o imperativo categórico. Souza (2009) elucida que este não se relaciona com a matéria da ação, isto é, com seu conteúdo, mas com a forma, com o princípio que fundamenta a vontade, e, por isso, este imperativo também pode ser denominado de o verdadeiro mandamento da moralidade.

Se a lei da moralidade existe de modo a priori, e se o mandamento nada mais é que a lei, podemos concluir que se um tal imperativo categórico de fato existe, sua forma não pode ser outra senão a seguinte: "Age apenas segundo uma máxima tal que possas ao mesmo tempo querer que ela se torne lei universal" (KANT, 2005, p.59).

Se no mais lato sentido chamamos natureza os efeitos produzidos pela universalidade da lei, isto é, a realidade que é determinada por leis universais, o imperativo categórico, como imperativo do dever, pode ainda se exprimir do seguinte modo (segunda fórmula do imperativo categórico, a fórmula da lei da natureza): "age como se a máxima de tua acção se devesse tornar, pela tua vontade, em lei universal da natureza" (KANT, 2005, p.59).

Por esta razão até mesmo o homem de entendimento comum tem diante de si uma bússola para guiar suas ações, pois basta perguntar a si mesmo se é possível querer que a máxima determinante de sua ação possa ser elevada à lei da natureza. Segundo Tugendhat (1996, p.148)

Kant diz com razão que eu teria de poder querer que a máxima, de acordo com a qual eu ajo, se torne lei universal. Claro está naturalmente que o querer de que se trata aqui é o querer plenamente comum ainda pré-moral, egoísta, pois o querer somente é moral na medida em que se deixa determinar pelo imperativo categórico. 
Para escapar da relação entre fins e meios, Kant (2005) formula uma suposição acerca de um fim em si como base para o imperativo categórico. Admitindo, porém, que haja alguma coisa cuja existência em si mesma tenha um valor absoluto e que, como fim em si mesmo, possa ser a base de leis determinadas, nessa coisa e só nela é que estará a base de um possível imperativo categórico, quer dizer, de uma lei prática. Kant (2005, p. 69), por sua vez, conclui:

\footnotetext{
O fundamento deste princípio é: A natureza racional existe como fim em si. É assim que o homem se representa necessariamente a sua própria existência; e, neste sentido, este princípio é um princípio subjectivo das ações humanas. Mas é também assim que qualquer outro ser racional se representa a sua existência, em virtude exactamente do mesmo princípio racional que é válido também para mim; é portanto simultaneamente um princípio objectivo, do qual como princípio prático supremo se têm de poder derivar todas as leis da vontade.
}

O fundamento de um imperativo categórico está naquilo que, por si mesmo, tem um valor absoluto e constitui um fim em si mesmo. Todo homem, porque é pessoa, existe como fim em si mesmo; daí que deva ser considerado sempre como fim e nunca como meio e isto é que distingue o homem dos seres irracionais e das coisas que têm um valor relativo e, por isso, podem ser utilizados como meios.

Da natureza racional Kant (2005, p. 69) deduz o imperativo categórico, ou seja, se existe um ser que é fim em si mesmo, tem de haver um princípio que demonstre esta finalidade. Segue-se daqui a terceira fórmula do imperativo categórico (a fórmula do autofim): "Age de tal maneira que uses a humanidade, tanto, na tua pessoa como na pessoa de qualquer outro, sempre e simultaneamente como fim e nunca simplesmente como meio". Desse modo, diz Tugendhat (1996, p.155): "o imperativo categórico vai desembocar no mandamento: não instrumentalizes ninguém! Pode-se também verter isto positivamente, dizendo: respeita-o como sujeito de direito! Ou com Kant pode se dizer: respeita-o em sua 'dignidade'!"

\section{CONCLUSÃO}

Ante as complexidades das relações sociais, o conflito entre as pessoas é inevitável. Desta forma o processo, enquanto procedimento dialético desenvolvido 
pelas partes para a pacificação da lide, não pode ser instrumento para obtenção de resultados ilícitos, escusos; deve todos os envolvidos zelar pela correta e justa composição do litígio.

É nesse sentido que o art. 14 do Código de Processo Civil elenca uma série de deveres a serem cumpridos pelas partes e todos que de qualquer forma participam do processo.

A lealdade processual deve ser vista como um princípio processual, observado sob o ângulo valorativo constitucional da dignidade da pessoa humana, como otimizador de uma relação jurisdicional justa em relação ao Estado, mas também perante a parte oponente.

Constitucionalmente, o princípio da dignidade da pessoa humana pode representar, por sua lógica aglutinadora, a continência da igualdade, da paridade de armas e da ética, tendo como resultado a justiça.

Nesse sentido, se a lealdade processual se presta a proporcionar a concretude de tais fins, pode ser considerado como valor em que se funda a dignidade da pessoa humana.

Esse exercício valorativo tem respaldo no pensamento de Immanuel Kant, já que $\circ$ agir com lealdade também representa o reconhecimento da dignidade existente entre as partes do processo, no sentido de que todos são merecedores de respeito e reconhecimento, não podendo as partes serem instrumentalizadas e utilizadas para fins escusos, o que representaria uma ofensa e lesão à dignidade daqueles que foram envolvidos e prejudicados.

\section{REFERÊNCIAS}

ALEXY, Robert. Teoria dos direitos fundamentais. Trad. Virgílio Afonso da Silva. São Paulo: Malheiros Editores, 2008.

BOBBIO, Noberto. Igualdad y dignidad de los Hombres. In: El tiempo de Ios derechos. Madri: Sistema, 1991.

BRITTO, Carlos Ayres. Teoria da constituição. Rio de Janeiro: Forense, 2003.

BUENO, Cassio Scarpinella. Curso sistematizado de direito processual civil. vol. 1. São Paulo: Saraiva, 2007. 
CÂMARA, Alexandre Freitas. Lições de direito processual civil. vol. I. 17 ed. Rio de Janeiro: Lumenjuris, 2008.

CARNELUTTI, Francesco. Instituzioni del processo civile italiano. vol. I. 5 ed. Roma: Foro it., 1956.

CHIOVENDA, Giuseppe. Instituições de direito processual civil. Trad. J. Guimarães Menegele. 3 ed. São Paulo: Saraiva, 1969.

CINTRA, Antônio Carlos Araujo; GRINOVER, Ada Pellegrini; DINAMARCO, Cândido Rangel. Teoria geral do processo. 27 ed. São Paulo: Malheiros Editores, 2011.

COMPARATO, Fábio Konder. Para viver a democracia. São Paulo: Brasiliense, 1989.

DINAMARCO, Cândido Rangel. Litisconsórcio. 5 ed. São Paulo: Malheiros, 1998.

DONIZETTI, Elpídio. Curso didático de direito processual civil. 17 ed. rev. ampl. atual. São Paulo: Atlas, 2013.

FERRAZ JUNIOR, Tercio Sampaio. Introdução do Estudo do Direito: técnica, decisão, dominação. 4. ed. São Paulo: Atlas, 2003.

GUERRA FILHO, Willis Santiago. Processo constitucional e direitos fundamentais. 4 ed. São Paulo: RCS, 2005.

HABERMAS, Jürgen. Direito e democracia: entre facticidade e validade. vol. 1. Tradução de Flávio Beno Siebeneichler. 2 ed. Rio de Janeiro: Tempo Brasileiro, 2003.

HESSE, Konrad. A força normativa da constituição. Porto Alegre: Fabris, 1991.

KANT, Immanuel. Fundamentação da metafísica dos costumes. Tradução Paulo Quintela. Lisboa: Edições 70, 2005

LACERDA, Galeano. Teoria geral do processo. Rio de Janeiro: Forense, 2007.

MARINONI, Luiz Guilherme. Curso de processo civil: teoria geral do processo. vol. 1. 2 ed. rev. atual. São Paulo: Revita dos Tribunais, 2007.

MORAES, Alexandre de. Direito Constitucional. 29.ed. São Paulo: Atlas, 2013.

NEVES, Daniel Amorin Assumpção. Manual de direito processual civil. 3 ed. São Paulo: Método, 2011.

SARLET, Ingo Wolfgang. Dignidade da pessoa humana e direitos fundamentais na Constituição Federal de 1988. 4. ed. Porto Alegre: Livraria do Advogado Editora, 2006. 
SILVA, Jose Afonso da. Curso de Direito Constitucional Positivo. 31.ed. São Paulo: Malheiros, 2008.

SOUZA, Hélio José dos Santos. O problema da motivação moral em Kant [online]. São Paulo: Editora UNESP; São Paulo: Cultura Acadêmica, 2009.

THEODORO JUNIOR, Humberto. Curso de direito processual civil: teoria geral do direito processual civil e processo de conhecimento. vol. I. 49 ed. Rio de Janeiro: Forense, 2008.

TUGENDHAT, Ernest. Lições sobre ética. 3 ed. Petrópolis: Vozes, 1996.

WAMBIER, Luiz Rodrigues; TALAMINI, Eduardo; ALMEIDA, Flávio Renato Correia de. Curso avançado de processo civil. vol. 1. 10 ed. rev. atual. ampl. São Paulo: Revista dos Tribunais, 2008. 